\title{
ANALISIS YURIDIS IMPLEMENTASI PROTOKOL KYOTO DI INDONESIA SEBAGAI NEGARA BERKEMBANG
}

\author{
Wita Setyaningrum \\ Fakultas Hukum Universitas Ahmad Dahlan \\ E-mail : wita.setyaningrum@yahoo.com
}

\begin{abstract}
ABSTRAK
Protokol Kyoto Protokol Kyoto adalah sebuah instrument hukum (legal instrument) yang dirancang untuk mengimplementasikan Konvensi Perubahan Iklim yang bertujuan untuk menstabilkan konsentrasi GRK agar tidak mengganggu sistem iklim Bumi. Indonesia sebagai salah satu negara yang turut meratifikasi Protokol tentu saja memiliki konsekuensi untuk mengimplementasikannya ke dalam undang-undang nasionalnya. Negara berkembang tidak diwajibkan menurunkan emisi tetapi bisa melakukannya secara sukarela dan diminta melaksanakan pembangunan berkelanjutan yang lebih bersih dan lebih ramah iklim. Untuk itu, negara maju diwajibkan memfasilitasi alih teknologi dan menyediakan dana bagi program pembangunan berkelanjutan yang ramah iklim.

Penulisan ini untuk mengetahui bagaimanakah implementasi protokol Kyoto di Indonesia dan untuk mengetahui kebijakan apasaja yang telah dirumuskan oleh pemerintah Indonesia, yaitu kementrian Lingkungan Hidup sebagai wujud pelaksanaan isi protokol. Selain itu, tujuan penelitian ini adalah untuk mengetahui efektifitas pelaksanaan peraturan perundangan terutama yang berhubungan dengan penyelamatan lingkungan serta untuk menganalisis konsistensi dari suatu peraturan perundangan yang dilaksanakan.

Indonesia sebagai salah satu negara yang meratifikasi protokol kyoto melakukan harmonisasi sebagai wujud implementasi isi protokol melalui UU No.32 Tahun 2009 tentang Perlindungan dan Pengelolaan Lingkungan Hidup. Walaupun tidak serta merta mengadopsi secara utuh ketentuan-ketentuan yang diatur dalam protokol, namun sudah tampak jelas adanya upaya pemerintah melalui kebijakankebijakan terkait perlindungan, pelestarian lingkungan dan pembangunan berkelanjutan sebagai dampak pemanasan global dan perubahan iklim.
\end{abstract}

Kata kunci : Pemanasan Global, Protokol Kyoto, UU No.32 Tahun 2009

\section{ABSTRACT}

The Kyoto Protocol is a legal instrument which is designed to implement the Convention on Climate Change aims to stabilize greenhouse gas concentrations in order not to disrupt the Earth's climate system. Indonesia as one of the participating countries to ratify the Protocol of course has consequences for implementing it into national law. Developing countries are not required to reduce emissions but may do so voluntarily and asked to implement the sustainable development of cleaner and more climate friendly. To that end, developed countries are required to facilitate the 
transfer of technology and provide funding for programs that climate-friendly sustainable development.

This study was to determine how the implementation of the Kyoto Protocol in Indonesia and to find out anything what policies that have been formulated by the Indonesian government, namely the Ministry of the Environment as a form of implementation of the protocol. In addition, the purpose of this study was to determine the effectiveness of the implementation of laws and regulations, especially related to saving the environment as well as to analyze the consistency of the rules and regulations implemented.

The results of the study, Indonesia as one of the countries that ratified the Kyoto Protocol as a form of harmonizing the content of the protocol implementation through Act No. 32 of 2009 on the Protection and Management of the Environment. Although not necessarily fully adopt the provisions stipulated in the protocol, but it was clear the government efforts through policies related to the protection, preservation of the environment and sustainable development as a result of global warming and climate change.

Keywords : Global Warming , The Kyoto Protocol , Act No. 32 of 2009

\section{Pendahuluan}

Pada pertengahan tahun 1980-an, berbagai pertemuan awal konferensi mulai diselenggarakan antar pemerintah untuk membicarakan masalah perubahan iklim. Mengingat pentingnya data-data terkini yang merespon masalah perubahan iklim, maka dibentuklah IPCC (Intergovernmental Panel on Climate Change) oleh UNEP (United Nations Environment Programme) dan WMO (World Meteorological Organization) pada tahun 1989.IPCC, sebuah panel ilmiah yang terdiri dari berbagai ilmuwan dari seluruh duniayang berdiri pada tahun 1988 atas prakarsa WMO dan UNEP guna memberikan informasi ilmiah yang terkini bagi para pembuat kebijakan di berbagai negara. (Armely Meiviana dkk, 2004:33)

Pada tahun 1990 IPCC mengeluarkan hasil penelitiannya yang pertama (First Assesment Report). Didalam laporannya dipastikan bahwa perubahan iklim merupakan sebuah ancaman bagi seluruh kehidupan umat manusia. IPCC menyerukan pentingnya sebuah kesepakatan global guna menanggulangi masalah perubahan iklim, mengingat hal ini merupakan masalah global yang harus diselesaikan secara global pula.

Majelis Umum PBB akhirnya menanggapi seruan IPCC untuk mengatasi masalah perubahan iklim secara global. Pada Desember 1990, PBB secara resmi membentuk badan antar pemerintah, yaitu Intergovernmental Negotiating Comittee (INC) untuk melakukan negosiasi ke arah Konvensi Perubahan Iklim. Pada bulan Mei 1992, INC menyepakati secara konsensus Kerangka Kerja Konvensi Perubahan Iklim PBB (United Nations Framework Convention on Climate ChangeUNFCCC). Kemudian pada Juni 1992, mulailah diselenggarakan KTT Bumi di Rio de Jeneiro, Brazil, dimana pada kesempatan ini Konvensi Perubahan Iklim mulai ditandatangani. 
Konvensi ini kemudian membagi negara-negara ke dalam 2 kelompok, yaitu negara yang maju yang terdaftar di dalam Annex I (dikenal dengan negara Annex I) serta negara berkembang yang tidak terdaftar di dalam negara Annex I (dikenal dengan negara non-Annex I). Di dalam Konvensi Perubahan Iklim dinyatakan bahwa negara Annex I maupun negara non-Annex I harus menyerahkan laporan yang dikenal dengan nama National Communication, yaitu laporan mengenai inventarisasi emisi GRK serta program dan kebijakan perubahan iklim nasionalnya. Namun, batas waktu penyerahan National Communication bagi negara non-Annex I lebih longgar daripada negara Annex I, sebagaimana disimpulkan oleh Armely Meiviana (2004:37).

Protokol Kyoto merupakan persetujuan dalam Persidangan Rangka Kerja PBB tentang Perubahan Iklim (UNFCCC), yang diterima di seluruh dunia tentang pemanasan global. Negara-negara yang bekerjasama untuk melaksanakan protokol ini di negara masing-masing berkomitmen untuk mengurangi pembebasan gas karbon dioksida dan lima gas rumah kaca lain, atau bekerjasama dalam perdagangan kontrak pembebasan gas jika mereka menjaga jumlah atau menambah pembebasan gas-gas tersebut, yang menjadi puncak gejala pemanasan global.

Nama resmi protokol ini ialah "Kyoto Protocol to the United Nations Framework Convention on Climate Change"(Protokol Kyoto dalam Persidangan Rangka Kerja PBB tentang Perubahan Iklim). Protokol ini telah dirumuskan di Kyoto, Jepang pada Disember 1997, dibuka untuk penandatanganan pada 16 Maret 1998 dan ditutup pada 15 Maret 1999. Persetujuan ini mulai berlaku pada 16 Februari 2005 setelah pengesahan resmi dilakukan oleh Rusia pada 18 November 2004.

Protokol Kyoto merupakan persetujuan sah oleh negara-negara perindustrian bahwa mereka akan mengurangi pembebasan emisi gas rumah kaca mereka secara kolektif sebesar $5.2 \%$ berbanding tahun 1990 (tetapi jika dibandingkan dengan jumlah pengurangan pembebasan gas rumah hijau jika tidak wujud protokol ini, pada tahun 2010, ialah kira-kira 29\%). Enam gas rumah kaca itu ialah karbon dioksida, metana, nitrus oksida, sulfur heksafluorida, kloroflurokarbon/CFC, dan perfluorokarbon/PFC.

Para pihak dalam Protokol Kyoto harus menyepakati target penurunan emisi, target waktu dan menerima pembatasanpembatasan yang dianggap rasional. Jadi, jelaslah bahwa Protokol Kyoto dengan tujuan utama mencapai tujuan konvensi dirancang, disepakati dan diimplementasikan untuk kepentingan semua pihak.

Indonesia sebagai salah satu negara yang telah meratifikasi Protokol Kyoto tentu saja memiliki konsekuensi untuk mengimplementasikan isi yang tertuang dalam protokol. Dalam ketentuan protokol, Indonesia sebagai negara berkembang dikelompokkan dalam negara Annex II dimana kewajibankewajiban yang diatur dalam konvensi berbeda dengan negara 
Annex I dalam hal ini negara-negara maju. Untuk mengetahui bagaimana efektifitas pelaksanaan Protokol Kyoto di Indonesia perlu dilakukan pengkajian secara mendalam terhadap kebijakan pemerintah Indonesia yang tertuang dalam bentuk peraturan perundangan yang terkait dengan masalah penyelamatan lingkungan, pemanasan global (global warming) dan perubahan iklim (climate change).

\section{Tinjauan Umum Tentang Protokol Kyoto}

Protokol Kyoto merupakan sebuah kesepakatan internasional yang menunjukkan sebuah upaya yang sangat serius dalam menghadapi perubahan iklim. Secara hukum Protokol Kyoto mewajibkan seluruh negara Annex I untuk menurunkan emisi GRK rata-rata sebesar 5,2\% dari tingkat emisi tahun 1990 pada periode tahun 2008-2012.Protokol Kyoto terdiri dari 28 pasal dan dua lampiran (annex) serta menetapkan penurunan emisi GRK akibat kegiatan manusia, mekanisme penurunan emisi, kelembagaan, serta prosedur penataan dan penyelesaian sengketa. Annex A mencantumkan jenis GRK yang diatur protokol yaitu : karbondioksida (C02), metana (CH4), nitrogen oksida (N20), hidrofluorokarbon (HFC), Perfluorokarbon (PFC) dan sulfur heksaflourida (SF6) beserta sumber emisinya seperti pembangkit energi, proses industri, pertanian dan pengolahan limbah.

Negara berkembang tidak diwajibkan menurunkan emisi tetapi bisa melakukannya secara sukarela dan diminta melaksanakan pembangunan berkelanjutan yang lebih bersih dan lebih ramah iklim. Untuk itu, negara maju diwajibkan memfasilitasi alih teknologi dan menyediakan dana bagi program pembangunan berkelanjutan yang ramah iklim.

Efektifitas Protokol Kyoto mensyaratkan agar diratifikasi oleh paling sedikit 55 negara, yang menunjukkan bahwa Protokol ini memerlukan partisispasi banyak negara, termasuk negara-negara berkembang. Sementara syarat minimum 55\% emisi negara maju harus dilibatkan, menunjukkan betapa pentingnya peranan negara maju sebagai pengemisi utama untuk bertindak langsung. Selama ini merekalah yang memberi kontribusi terbesar dalam peningkatan konsentrasi GRK hingga pada keadaan sekarang. Dalam tabel terakhir dari lampiran Protokol Kyoto yang digunakan untuk menentukan efektifitas Protokol kyoto secara prosentase kontribusi terbesar adalah AS $(36,1)$, Rusia $(17,4)$, Jepang $(8,5)$, Jerman $(7,4)$, Inggris $(4,2)$, Kanada $(3,3)$, Italia $(3,1)$, Polandia (3), Perancis (2,7), Australia (2,1), empat negara antara 1-2\%, 17 negara di bawah $1 \%$ dan sisanya 3 negara $0 \%$.

Protokol Kyoto menyatakan bahwa negara Annex I pada Konvensi Perubahan Iklim harus mengurangi emisi melalui kebijakan dan langkah-langkah di dalam negeri, antara lain meningkatkan efisiensi penggunaan energi, perlindungan perosot (peresap) GRK, teknologi yang ramah iklim dsb. Selain itu, untuk memudahkan negara maju memenuhi sasaran penurunan emisi, Protokol Kyoto juga 
mengatur mekanisme fleksibel, yakni:

1. Implementasi Bersama (Joint Implementation);

Yaitu mekanisme penurunan emisi dimana negara-negara Annex I dapat mengalihkan pengurangan emisi melalui proyek bersama dengan tujuan mengurangi emisi. Pada awalnya perundingan tentang JI menimbulkan perdebatan mengenai dimasukkannya negara berkembang dalam mekanisme ini. Negara-negara OPEC menolak dengan alasan akan menjauhkan negara majudari kemungkinan menandatangani Protokol Kyoto.(2003:48) India dan Cina mengharapkan kekompakan G77+Cina dan akhirnya memutuskan bahwa negara berkembang tidak akan ikut dengan JI di bawah Protokol Kyoto.

Ada 4 alasan mengapa negara berkembang harus menolak JI, diantaranya adalah :

a. Biaya transaksi yang tinggi, sehingga mengurangi keuntungan negara berkembang

b. Tidak jelasnya penentuan garis awal sebelum proyek dilaksanakan dan kemungkinan adanya kebocoran (leakage) yang mendorong terjadinya kolusi antara kedua belah pihak

c. Isu kesetaraan yang sulit dipertahankan karena negara maju akan mengubah strateginya jika biaya proyek JI sudah terlalu mahal sementara negara berkembang belum siap memasuki indistri rendah emisi yang teknologinya belum dikuasai.

d. JI adalah bentuk neokolonialisme yang harus ditolak karena negaranegara maju akan memiliki posisi tawar yang makin kuat karena kemampuan teknologinya semakin baik, sementara emisinya dibayar dengan murah di negara berkembang.

2. Perdagangan

Emisi (Emission Trading);

Ini adalah mekanisme perdagangan emisi yang hanya dapat dilakukan antar negara industri untuk memudahkan mencapai target. Negara industri yang emisi GRKnya di bawah batas yang diizinkan dapat menjual kelebihan jatah emisinya ke negara industri lain yang tidak dapat memenuhi kewajibannya. Namun, jumlah emisi GRK yang diperdagangkan dibatasi agar negara pembeli emisi tetap memenuhi kewajibannya.

3. Mekanisme Pembangunan Bersih (Clean Development Mechanism--CDM)

Pasal 12 Protokol Kyoto menguraikan prosedur penurunan emisi GRK dalam rangka kerja sama negara industri dengan negara berkembang. Mekanisme ini diharapkan membantu negara Annex I mencapai target pengurangan emisi dan negara non Annex I dapat melaksanakan program pembangunan berkelanjutan. Caranya adalah negara Annex I melakukan investasi dalam program pengurangan emisi atau program yang berpotensi mengurangi emisi dan/atau menyerap GRK di negara berkembang. Hasilnya akan dihitung sebagai pengurangan emisi di negara Annex I yang melakukan investasi tersebut. Mekanisme ini melibatkan berbagai persyaratan dan diawasi oleh 
sebuah badan operasional (Executive Board) yang ditunjuk COP. Dalam pelaksanaannya CDM adalah murni bisnis jual beli emisi.

\section{Negara Annex I dan Negara Non- Annex I}

Negara Annex I adalah negaranegara yang telah menyumbangkan pada GRK akibat kegiatan manusia sejak revolusi industri tahun 1850-an, yaitu: Amerika Serikat, Australia, Austria, Belanda, Belarusia, Belgia, Bulgaria, Ceko, Denmark, Estonia, Finlandia, Federasi Rusia, Jerman, Hongaria, Irlandia, Italia, Inggris, Islandia, Jepang, Kanada, Kroasia, Latvia, Liechtenstein, Lithuania, Luxemburg, Monako, Norwegia, Polandia, Portugal, Perancis, Rumania, Selandia Baru, Slovakia, Slovenia, Spanyol, Swedia, Swiss, Turki, Ukraina, Uni Eropa dan Yunani.Sedangkan Negara Non-Annex I adalah negaranegara yang tidak termasuk dalam Annex I, yang kontribusinya terhadap GRK jauh lebih sedikit serta memiliki pertumbuhan ekonomi yang jauh lebih rendah. Indonesia termasuk dalam negara Non-Annex I.

\section{Kebijakan Dalam Implementasi Protokol Kyoto di Indonesia}

Protokol Kyoto adalah sebuah instrument hukum (legal instrument) yang dirancang untuk mengimplementasikan Konvensi Perubahan Iklim yang bertujuan untuk menstabilkan konsentrasi GRK agar tidak mengganggu sistem iklim Bumi. Setelah diadopsi pada tanggal 11 Desember 1997, Protokol Kyoto dibuka untuk ditandatangani pada tanggal 16 Maret 1998. Sesuai dengan ketentuan Pasal 25, Protokol Kyoto secara efektif akan berlaku 90 hari setelah diratifikasi oleh paling sedikit 55 Pihak Konvensi, termasuk negaranegara maju dengan total emisi karbon dioksida paling sedikit 55 persen dari total emisi tahun 1990 dari kelompok-kelompok negara industri. (Daniel Murdiyarso, 2007:8).

Protokol Kyoto sebagai instrument perjanjian internasional secara resmi berlaku pada tanggal 16 Februari 2005 setelah dilakukan ratifikasi secara resmi oleh Rusia pada tanggal 18 November 2009. Pengesahan atas sebuah perjanjian internasional melalui ratifikasi akan mempunyai implikasi yang luas bagi suatu negara, seperti implikasi di bidang politik, hukum, ekonomi dan kelembagaan.Sebagai negara berkembang Indonesia yang tidak memiliki obligasi untuk menurunkan emisinya, telah meratifikasi Protokol Kyoto.

Mekanisme yang diatur dalam Protokol Kyoto mengelompokkan negara-negara menggunakan istilah Negara Annex I dan Negara NonAnnex I.Negara Annex I adalah negara-negara yang telah menyumbangkan pada GRK akibat kegiatan manusia sejak revolusi industri tahun 1850-an, yaitu: Amerika Serikat, Australia, Austria, Belanda, Belarusia, Belgia, Bulgaria, Ceko, Denmark, Estonia, Finlandia, Federasi Rusia, Jerman, Hongaria, Irlandia, Italia, Inggris, Islandia, Jepang, Kanada, Kroasia, Latvia, Liechtenstein, Lithuania, Luxemburg, Monako, Norwegia, Polandia, Portugal, Perancis, Rumania, Selandia Baru, Slovakia, Slovenia, Spanyol, Swedia, Swiss, 
Turki, Ukraina, Uni Eropa dan Yunani.Sedangkan Negara Non-Annex I adalah negara-negara yang tidak termasuk dalam Annex I, yang kontribusinya terhadap GRK jauh lebih sedikit serta memiliki pertumbuhan ekonomi yang jauh lebih rendah. Indonesia termasuk dalam negara NonAnnex I. (Wita Setyaningrum, 2009:32) NSS, dengan meminjam model perencanaan energi MARKAL (Market Allocation), memproyeksikan komposisi pemakaian energi primer (primary energy mix) di Indonesia hingga tahun 2025. Diperlihatkan pangsa konsumsi minyak bumi, gas bumi, batubara, tenaga air (hydropower) dan biomass. (Hanan Nugroho, 2004:7) Kecenderungan pertumbuhan konsumsi energi primer yang menonjol tampak pada pemakaian batubara. Berdasarkan proyeksi konsumsi energi primer tersebut, kemudian diperkirakan besaran emisi karbondioksida $\left(\mathrm{CO}_{2}\right.$ ) yang dihasilkan dari kegiatan pemanfaatan energi.

Tabel 1. Perkiraan emisi karbondioksida dari sektor energi Indonesia hingga tahun 2025

\begin{tabular}{|l|cccccc|c|}
\hline \multirow{2}{*}{ Sektor } & \multicolumn{5}{|c|}{ Total emisi CO2 (juta TON) } & $\begin{array}{c}\text { Pertumbuhan } \\
\text { Rata-rata } \\
\text { (\% per tahun) }\end{array}$ \\
\cline { 2 - 7 } & 2000 & 2005 & 2010 & 2015 & 2020 & 2025 & 2.4 \\
Industri & 58 & 66 & 73 & 91 & 109 & 141 & 0.4 \\
Rumah Tangga & 21 & 22 & 23 & 23 & 22 & 25 & 3.4 \\
Pbk. Tenaga Listrik & 54 & 61 & 76 & 99 & 128 & 168 & 5.1 \\
Industri Energi & 40 & 30 & 35 & 27 & 48 & 63 & 1.9 \\
\hline TOTAL & 228 & 246 & 298 & 392 & 526 & 672 & 3.3 \\
\hline
\end{tabular}

Sumber: NSS on CDM in Indonesia, 2001.

Dari table diatas tampak jelas adanya peningkatan penggunaan emisi karbondioksida (CO2) di Indonesia pada tiap tahunnya, sehingga dikhawatirkan akan menambah laju kerusakan lingkungan terutama pada efek gas rumah kaca (GRK) yang secara langsung merusak lapisan atmosfer bumi dan memicu terjadinya pemanasan global (global warming).

Seiring perkembangan tehnologi dan pembangunan di dunia selain meninggalkan sisi positif ternyata juga menimbulkan dampak terhadap perusakan serta pencemaran terhadap lingkungan. Kualitas lingkungan yang buruk apabila tidak dicegah akan menimbulkan persoalan-persoalan terhadap lingkungan yang juga menimbulkan kehancuran bagi manusia dan mahkluk hidup lainnya. Tabel diatas sedikit menjelaskan gambaran konsumsi bahan bakar energi (emisi) di Indonesia yang membawa pengaruh terhadap fenomena efek gas rumah kaca (GRK) yang selanjutnya menimbulkan pemanasan global (global warming) yang berimplikasi terhadap perubahan iklim di dunia. UndangUndang Nomor 32 Tahun 2009 Tentang PPLH telah mengatur mengenai perubahan iklim 
sebagaimana ditegaskan di dalam konsiderans dari undang-undang tersebut dan juga dijabarkan dalam Pasal 1 butir 19 bahwa perubahan iklim adalah berubahnya iklim yang diakibatkan langsung atau tidak langsung oleh aktivitas manusia sehingga menyebabkan perubahan komposisi atmosfir secara global dan selain itu juga berupa perubahan variabilitas iklim alamiah yang teramati pada kurun waktu yang dapat dibandingkan.

Indonesia sebelum meratifikasi Protokol Kyoto telah memiliki kebijakan lingkungan hidup yang disebut AMDAL. Kebijakan Lingkungan Hidup dan Protokol Kyoto telah mendorong Indonesia sebagai negara kepulauan yang rentan terhadap dampak perubahan iklim merumuskan kebijakan lingkungan dengan melakukan agenda mitigasi dan adaptasi. Agenda mitigasi yang dilakukan Pemerintah Indonesia menyangkut:

1. Konservasi energy

2. Bidang transportasi

3. Sektor industry

4. Penerapan teknologi ramah lingkungan pada sektor pembangkit listrik

5. Penggunaan energi baru terbarukan seperti pemanfaatan ternaga surya, angin, ombak, energi panas bumi dan pemanfaatan sampah.

Sementara agenda adaptasi dalam strategi pembangunan yang direncanakan antara lain dilakukan melalui:

1. Program pengurangan risiko bencana terkait iklim melalui program penghutanan kembali, penghijauan terutama di kawasan hutan/lahan yang kritis.

2. Penyebarluasan informasi perubahan iklim dan informasi adaptasi

3. Peningkatan kapasitas mengintegrasikan perubahan iklim kedalam perencanaan, perancangan infrastruktur, pengelolaan konfril dan pembagian kawasan air tanah untuk institusi pengelolaan air

4. Pengarus-utamaan adaptasi perubahan iklim kedalam kebijakan dan program dengan fokus pada pengeloaan bencana, sumberdaya air, pertanian, kesehatan dan industri

5. Pengembangan isu perubahan iklim ke dalam kurikulum sekolah menengah dan perguruan tinggi;

Kebijakan Indonesia

meratifikasi Protokol Kyoto memberi peluang Indonesia secara ekonomi sebagai negara non-Annex 1 melalui penerapan proyek CDM (Clean Development Mechanism).CDM merupakan mekanisme Protokol Kyoto yang memungkinkan negara Annex-I dan negara berkembang bekerja-sama untuk melakukan "pembangunan bersih". Dengan fasilitas CDM, negara Annex-I dapat memenuhi kewajiban pengurangan emisinya dengan melakukan proyek "pengurangan emisi" di suatu negara berkembang dan negara berkembang mendapatkan kompensasi finansial dan teknologi dari kerja-sama tersebut. Tujuan CDM sebagaimana ditegaskan oleh Protokol Kyoto (Pasal 12) adalah 
membantu negara berkembang melakukan pembangunan berkelanjutan (sustainable development) dan turut menyumbang bagi pencapaian tujuan pengurangan emisi global, serta untuk membantu negara Annex-I mencapai target pengurangan emisi mereka. Investasi negara Annex-I di negara berkembang yang menghasilkan penurunan emisi akan disertifikasi dan kredit dari "pengurangan emisi yang disertifikasi" (certified emission reduction, CER) tersebut akan diberikan kepada negara Annex-I. (Hanan Nugroho, 2004:5)

Dikeluarkannya UU No.32 Tahun 2009 Tentang Perlindungan dan Pengelolaan Lingkungan Hidup (PPLH) sebagai wujud upaya pemerintah dalam menjaga dan melestarikan lingkungan. Prinsip sustainable development dalam setiap aspek pembangunan di Indonesia harus senantiasa dijaga agar keberlangsungan kehidupan tetap terjaga hingga generasi yang akan datang. Hal ini sejalan dengan tujuan dirumuskannya Protokol Kyoto sebagai

\begin{tabular}{|l|l|l|}
\hline dirumuskannya Protokol Kyoto sebagai & (Tabel. 2) \\
\hline Lingkup & \multicolumn{1}{|c|}{ Protokol Kyoto } & \multicolumn{1}{c|}{ UU No.32 Tahun 2009 } \\
\hline Tujuan & 1. Protokol Kyoto dari Konvensi & Tujuan yang terkait dengan \\
& Kerangka Kerja Perserikatan & Protokol, tercantum dalam \\
& Bangsa-Bangsa Tentang & konsiderans poin b dan e yang \\
& Perubahan Iklim (Kyoto & isinya : \\
& Protocol to The United Nations & 1. Bahwa pembangunan \\
& Framework Convention on & ekonomi nasional \\
& Climate Change) adalah & sebagaimana diamanatkan \\
& kesepakatan yang mengatur & Undang-Undang Dasar \\
& upaya penurunan emisi GRK & Negara Republik Indonesia \\
& oleh negara maju, secara & Tahun 1945 diselenggarakan \\
& individu atau bersama-sama. & berdasarkan prinsip \\
& 2. Tujuan Protokol & pembangunan berkelanjutan \\
& Kyotomengantisipasi dan & dan berwawasan lingkungan. \\
& mengurangi dampak global & 2. Bahwa pemanasan global \\
& warming dan climate change & yangsemakin \\
& dengan prinsip sustainable & meningkatmengakibatkan \\
& development. & perubahan iklimsehingga \\
\hline
\end{tabular}

kerangka hukum yang mengatur upaya dalam mengantisipasi dampak adanya global warming dan climate change.

Konsistensi Pelaksanaan UU N0.32 Tahun 2009 Tentang Perlindungan dan Pengelolaan Lingkungan Hidup Dengan Mekanisme Protokol Kyoto

Konsekuensi Indonesia meratifikasi suatu Instrument Internasional dalam hal ini Protokol Kyoto adalah dilakukannya harmonisasi Protokol Kyoto ke dalam Undang-Undang nasional Indonesia.Melalui UU No. 32 Tahun 2009 Tentang Perlindungan dan Pengelolaan Lingkungan Hidup mekanisme implementasi Protokol Kyoto tergambar jelas arah dan pelaksanaannya.

Implementasi Protokol Kyoto ke dalam UU No.32 Tahun 2009 lebih spesifik dapat digambarkan dalam tabel sebagai berikut : (Tabel. 2) 


\begin{tabular}{|c|c|c|}
\hline & & $\begin{array}{l}\text { memperparah penurunan } \\
\text { kualitas lingkungan hidup } \\
\text { karena itu perlu dilakukan } \\
\text { perlindungan dan } \\
\text { pengelolaan lingkungan } \\
\text { hidup; }\end{array}$ \\
\hline Target & $\begin{array}{l}\text { Tercapainya target penurunan } \\
\text { emisi yang dikenal dengan nama } \\
\text { quantified emission limitation and } \\
\text { reduction commitments (QELROs) } \\
\text { adalah inti dari Protokol } \\
\text { Kyoto.Sebagaimana diuraikan } \\
\text { dalam Pasal 3, target Kyoto } \\
\text { memilikibeberapa implikasi } \\
\text { sebagai berikut: } \\
\text { 1. Mengikat secara hukum (legally } \\
\text { binding) porito } \\
\text { 2. Adanya periode komitmen } \\
\text { (commitment period) } \\
\text { 3. Digunakannya rosot (sink) } \\
\text { untuk mencapai target } \\
\text { 4. Adanya jatah emisi (assigned } \\
\text { amount) setiap pihak Annex I } \\
\text { 5. Dimasukkannya enam jenis } \\
\text { GRK (basket of gases) dan } \\
\text { disetarakan dengan CO }{ }_{2}\end{array}$ & $\begin{array}{l}\text { Tujuan dirumuskannya UU } \\
\text { No.32 Tahun } 2009 \text { Tentang } \\
\text { PPLH yang secara langsung } \\
\text { berintegrasi dengan isi Protokol } \\
\text { Kyoto diantaranya adalah: } \\
\text { 1. Dalam Bab II bagian kesatu } \\
\text { (Pasal 3) Tentang Tujuan } \\
\text { yang mengatur beberapa hal, } \\
\text { diantaranya: } \\
\text { a. melindungi wilayah Negara } \\
\text { Kesatuan Republik Indonesia } \\
\text { dari pencemaran dan/atau } \\
\text { kerusakan } \\
\text { lingkungan hidup; } \\
\text { b. menjamin keselamatan, } \\
\text { kesehatan, dan kehidupan } \\
\text { manusia; } \\
\text { c. menjamin kelangsungan } \\
\text { kehidupan makhluk hidup } \\
\text { dan kelestarian ekosistem; } \\
\text { d. menjaga kelestarian fungsi } \\
\text { lingkungan hidup; } \\
\text { e. mencapai keserasian, } \\
\text { keselarasan, dan } \\
\text { keseimbangan lingkungan } \\
\text { hidup; } \\
\text { f. menjamin terpenuhinya } \\
\text { keadilan generasi masa kini } \\
\text { dan generasi masa depan; } \\
\text { g. menjamin pemenuhan dan } \\
\text { perlindungan hak atas } \\
\text { lingkungan hidup sebagai } \\
\text { bagian dari hak } \\
\text { asasimanusia; } \\
\text { h. mengendalikan } \\
\text { pemanfaatan sumber daya } \\
\text { alam secara bijaksana; } \\
\text { i. mewujudkan pembangunan } \\
\text { berkelanjutan; dan }\end{array}$ \\
\hline
\end{tabular}




\begin{tabular}{|c|c|c|}
\hline & & $\begin{array}{l}\text { j. mengantisipasi isu } \\
\text { lingkungan global. } \\
\text { 2. Pelaksanaan Sanksi secara } \\
\text { tegas, yaitu sanksi } \\
\text { administrative yang diatur } \\
\text { dalam Pasal 77, } 78 \text { dan } 79 . \\
\text { Dan adanya eksekusi paksa } \\
\text { yang diatur secara tegas } \\
\text { dalam Pasal } 80 \text { dalam hal ini } \\
\text { adalah Paksaan Pemerintah. }\end{array}$ \\
\hline $\begin{array}{l}\text { Mekanism } \\
\text { e }\end{array}$ & $\begin{array}{l}\text { Protokol Kyoto menyatakan } \\
\text { bahwa negara Annex I pada } \\
\text { Konvensi Perubahan Iklim harus } \\
\text { mengurangi emisi melalui } \\
\text { kebijakan dan langkah-langkah di } \\
\text { dalam negeri, antara lain } \\
\text { meningkatkan efisiensi } \\
\text { penggunaan energi, perlindungan } \\
\text { perosot (peresap) GRK, teknologi } \\
\text { yang ramah iklim dsb. }\end{array}$ & $\begin{array}{l}\text { Indonesia merupakan negara } \\
\text { Non-Annex I yang tidak } \\
\text { terbebani secara langsung } \\
\text { dalam upaya penurun emisi. } \\
\text { Namun demikian, dalam } \\
\text { kebijakannya yang tertuang } \\
\text { dalam Paragraf } 1 \text { mengenai } \\
\text { Baku Mutu Lingkungan Hidup } \\
\text { yang diatur dalam Pasal 15, 16, } \\
17 \text { dan } 18 \text { tampak nyata sekali } \\
\text { adanya komitmen dari } \\
\text { pemerintah dalam upaya } \\
\text { penyelamatan dan pelestarian } \\
\text { lingkungan hidup. }\end{array}$ \\
\hline $\begin{array}{l}\text { Protol } \\
\text { Pasal } \\
\text { beriks } \\
\text { 1. Per } \\
\text { dae } \\
\text { unt } \\
\text { pri } \\
\text { ber } \\
\text { das } \\
\text { pen } \\
\text { dan } \\
\text { dan } \\
\text { Per } \\
\text { dae } \\
\text { KLI } \\
\text { pad } \\
\text { per } \\
\text { a. I } \\
\text { ( }\end{array}$ & $\begin{array}{l}\text { lekanisme implementasi isi } \\
\text { ol yang tertuang dalam } \\
15 \text { yang berbunyi sebagai } \\
\text { t: } \\
\text { erintah dan pemerintah } \\
\text { rah wajib membuat KLHS } \\
\text { dk memastikan bahwa } \\
\text { sippembangunan } \\
\text { relanjutan telah menjadi } \\
\text { ar dan terintegrasi dalam } \\
\text { bangunan suatu wilayah } \\
\text { /atau kebijakan, rencana, } \\
\text { /atau program. } \\
\text { lerintah dan pemerintah } \\
\text { rah wajib melaksanakan } \\
\text { IS sebagaimana dimaksud } \\
\text { a ayat (1) ke dalam } \\
\text { yusunan atau evaluasi: } \\
\text { encana tata ruang wilayah } \\
\text { RTRW) beserta rencana }\end{array}$ & 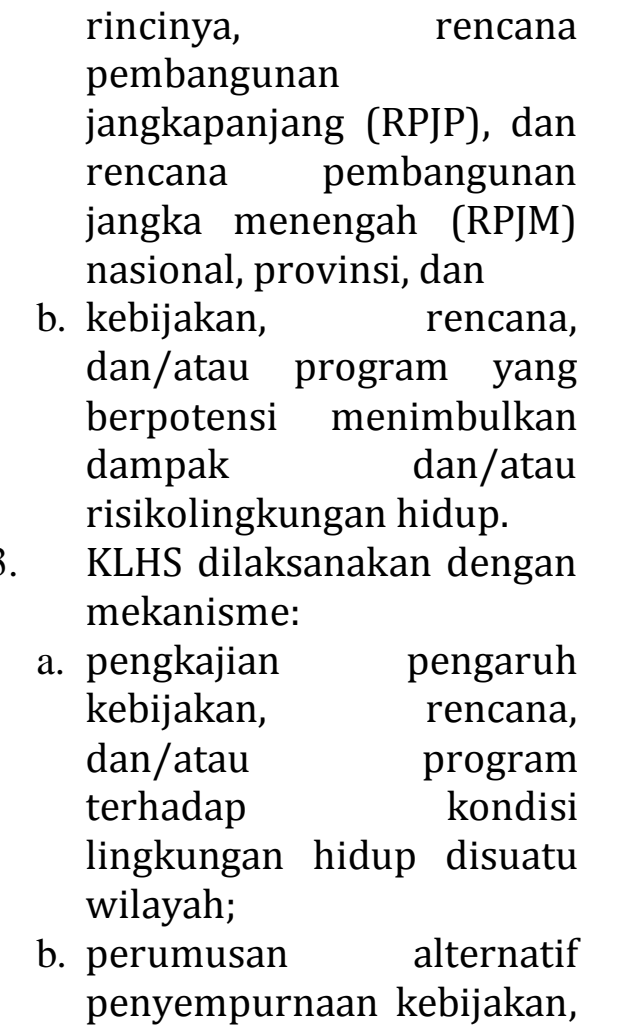 \\
\hline
\end{tabular}


rencana, dan/atau program;

c. rekomendasi perbaikan untuk pengambilan

keputusan

kebijakan, rencana, dan/atau program yang mengintegrasikan prinsip pembangunan berkelanjutan.

Walaupun tidak semua ketentuan-ketentuan yang terkandung dalam protokol dapat diharmonisasikan ke dalam hukum nasional, Indonesia sebagai negara pihak peserta konvensi memiliki andil yang cukup baik dalam merespon dalam melakukan upaya penyelamatan dan pelestarian lingkungan. Berakhirnya batas waktu yang disepakati dalam pelaksanaan Protokol Kyoto pada 2012 kemarin, dan munculnya ketentuan REDD (Reducing Emission for Degradation Deforestation) sebagai kelanjutan dari protokol tidak menyurutkan Indonesia melakukan upaya penurunan emisi. Indonesia tetap memiliki komitmen dalam upaya penurunan emisi dan menekan laju gas rumah kaca melalui kebijakan-kebijakan, diantaranya dalam pengelolaan BBM, migrasi bahan bakar minyak ke bahan bakar gas, izin pendirian usaha dan bangunan berbasis AMDAL, menghentikan impor peralatan/produk berbahan Freon atau CFC (Chloroflourocarbon) yang menyebabkan kerusakan lapisan ozon bumi dan kebijakan- kebijakan lain terkait upaya penyelamatan lingkungan.

\section{Simpulan}

Protokol Kyoto adalah sebuah instrument hukum (legal instrument) yang dirancang untuk mengimplementasikan Konvensi Perubahan Iklim yang bertujuan untuk menstabilkan konsentrasi GRK agar tidak mengganggu sistem iklim Bumi.Indonesia sebagai salah satu negara yang meratifikasi protokol melakukan harmonisasi sebagai wujud implementasi isi protokol melalui UU No.32 Tahun 2009 tentang Perlindungan dan Pengelolaan Lingkungan Hidup.

Kebijakan Lingkungan Hidup dan Protokol Kyoto telah mendorong Indonesia sebagai negara kepulauan yang rentan terhadap dampak perubahan iklim merumuskan kebijakan lingkungan dengan melakukan agenda mitigasi dan adaptasi. Agenda mitigasi yang dilakukan Pemerintah Indonesia menyangkut konservasi energi, bidang transportasisektor industri, penerapan teknologi ramah lingkungan pada sektor pembangkit listrik, penggunaan energi baru terbarukan seperti pemanfaatan ternaga surya, angin, ombak, energi panas bumi dan pemanfaatan sampah.

Sementara agenda adaptasi dalam strategi pembangunan yang direncanakan antara lain dilakukan melalui program pengurangan risiko bencana terkait iklim melalui program 


\begin{abstract}
penghutanan kembali, penghijauan terutama di kawasan hutan/lahan yang kritis, penyebarluasan informasi perubahan iklim dan informasi adaptasi, peningkatan kapasitas mengintegrasikan perubahan iklim kedalam perencanaan, perancangan infrastruktur, pengelolaan konfril dan pembagian kawasan air tanah untuk institusi pengelolaan air, pengarus-utamaan adaptasi perubahan iklim kedalam kebijakan dan program dengan fokus pada pengeloaan bencana, sumberdaya air, pertanian, kesehatan dan industri pengembangan isu perubahan iklim ke dalam kurikulum sekolah menengah dan perguruan tinggi.

Walaupun tidak serta merta mengadopsi secara utuh ketentuan-ketentuan yang diatur dalam protokol, namun sudah tampak jelas adanya upaya pemerintah melalui kebijakankebijakan terkait perlindungan, pelestarian lingkungan dan pembangunan berkelanjutan sebagai dampak pemanasan global dan perubahan iklim.
\end{abstract}

\section{Daftar Pustaka}

Heinrich Böll Foundation. 2002. The Jo'burg Memo: Keadilan yang Wajar dalam Dunia yang Rapuh Memorandum untuk World Summit on Sustainable Development. Edisi Kedua. Berlin-Germany : the Heinrich Böll Foundation

Murdiyarso. Daniel. 2003. Sepuluh Tahun Perjalanan Negosiasi
Konvensi Perbahan Iklim. Jakarta : Kompas 2007. Protokol Kyoto Implikasi Bagi Negara Berkembang. Jakarta: Kompas

Soekanto, Soerjono. 2006. Pengantar Penelitian Hukum. Jakarta: UI Press, 1985, Pengantar hukum Normatif (Suatu Tinjauan singkat), Jakarta : Raja Grafindo Persada

Triatmodjo, Marsudi. 1999. Penerapan Precautionary Principle: Pergeseran Paradigma Hukum Lingkungan Internasiona. Yogyakarta: Gama Press

UNDP. 2001. Sustainable Development, Energy and the Environtment : UNDP's Climate Change Initiatives. UNDP.

\section{Artikel, Publikasi dan Jurnal}

Artikel Depkominfo. 2007. Perubahan Iklim (Global Climate Change). diakses pada

http://www.blogs.depkomi nfo.go.id/artikel/2007/11/ 22/perubahan-iklimglobal-climate-change/

Naskah Akademik Pengesahan Protokol Kyoto, dari http://www.google.com/a dobe-reader diakses pada tanggal 20 Januari 2009

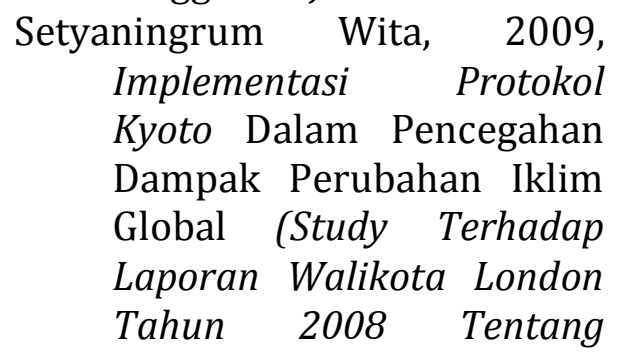


Strategi Adaptasi Kota London Dalam Pencegahan Dampak Akibat Perubahan Iklim Global), Tesis : UGM

\section{Perundang-undangan}

\section{Convention on Climate Change diakses dari http://www.google.com}

Rio Declaration on Environment and Development, 1992 dari http://www.google.com

The Kyoto Protocol to The United Nations Framework Convention on Climate Change, 1999 diakses dari http://www.google.com

UNEP, 1999, Convention on Climate Change, Geneva : UNEP/IUC

UU No.32 Tahun 2009 Tentang Perlindungan dan Pengelolaan Lingkungan Hidup

\section{Internet}

Burhan Latief, H.A, 2007, Perubahan Iklim Global, dari http://www.google.com/ad obe-reader diakses pada tanggal 20 Januari 2009

CIFOR (Center For International Forestry Research), 2005, Carbon Brief, diakses pada http://www.cifor.cgiar.org/ publications/pdf_files/carbo brief/carbobrief0503.pdf

KLH (Kementrian Negara Lingkungan Hidup) \& JICA (Japan International Cooperation Agency), 2004, Konvensi Perubahan Iklim, diakses pada

http://www.menlh.go.id/i ndex.php

Meiviana, Armely dkk, 2004, Bumi Makin Panas (Ancaman Perubahan Iklim di Indonesia), Kementrian Lingkungan Hidup Republik Indonesia dan Pelangi (Yayasan Pelangi Indonesia), hlm.8 Diakses pada

Http://www.pelangi.or.id

NN, 2007, Pemanasan Global dan Dampak yang Ditimbulkan, diakses dari http://wahdisblog.blogspo t.com/2007/12/pemanasa n-global-dan-dampakyang.html pada 6 April 2008 21:36:05 GMT.

NN, 2007, Perubahan Iklim Dunia, diakses dari http://www.atanitokyo.blo gspot.com/2008/3/peruba han-iklim-dunia.html pada tanggal 10 April 2008.

Nugroho Hanan, 2004, Ratifikasi Protokol Kyoto, Mekanisme Pembangunan Bersih dan Pengembangan Sektor Energi Indonesia : Catatan Strategis, diakses dari www.kompas.com pada 28januari 2014

Wikipedia, Protokol Kyoto, diakses pada tanggal 10 April 2008 dari http://www.id.wikipedia.o rg/wiki/protokol-kyoto 